KARLO BABOJELIĆ, M.Sc. ${ }^{1}$

(Corresponding author)

E-mail: kbabojelic@fpz.unizg.hr

LUKA NOVAČKO, Ph.D. ${ }^{1}$

E-mail: luka.novacko@fpz.unizg.hr

${ }^{1}$ University of Zagreb

Faculty of Transport and Traffic Sciences

Vukelićeva 4, 10000 Zagreb, Croatia
Transport and Sustainable Development

Review

Submitted: 17 Feb. 2020

Accepted: 2 Aug. 2020

\title{
MODELLING OF DRIVER AND PEDESTRIAN BEHAVIOUR - A HISTORICAL REVIEW
}

\begin{abstract}
Driver and pedestrian behaviour significantly affect the safety and the flow of traffic at the microscopic and macroscopic levels. The driver behaviour models describe the driver decisions made in different traffic flow conditions. Modelling the pedestrian behaviour plays an essential role in the analysis of pedestrian flows in the areas such as public transit terminals, pedestrian zones, evacuations, etc. Driver behaviour models, integrated into simulation tools, can be divided into car-following models and lane-changing models. The simulation tools are used to replicate traffic flows and infer certain regularities. Particular model parameters must be appropriately calibrated to approximate the realistic traffic flow conditions. This paper describes the existing car-following models, lane-changing models, and pedestrian behaviour models. Further, it underlines the importance of calibrating the parameters of microsimulation models to replicate realistic traffic flow conditions and sets the guidelines for future research related to the development of new models and the improvement of the existing ones.
\end{abstract}

\section{KEYWORDS}

driver and pedestrian behaviour models; car-following; lane-changing; calibration;

\section{INTRODUCTION}

The main aim of the paper is to stratify the existing car-following, lane-changing, and pedestrian behaviour models. Spatial constraints render the expansion of the current road capacity impossible, leaving efficient traffic flow management as one of the methods of dealing with traffic congestion. Intervening in real-world traffic situations, without prior analysis and evaluation often results in errors and requires significant financial resources. Different simulation tools that integrate driver and pedestrian behaviour models are therefore used to evaluate various traffic situations and various solutions and to facilitate the decision-making. Simulation models have the ability to closely replicate actual traffic situations by modelling each vehicle and pedestrian in the network. The fundamental element of microscopic simulation models is driver and pedestrian behaviour in a traffic network, i.e. Car Following (CF), Lane Change (LC), route choice, gap acceptance, and regarding pedestrians, avoiding other pedestrians and obstacles. Car-following models describe the vehicle longitudinal movement, while lane-changing models describe the selection of the target lane. Driver behaviour can be described as speed adjustment, acceleration/deceleration, lane selection, and space gap adjustment according to road conditions. In the last two decades, several review papers were written on the car-following [1-3], and lane-change [4-6] subject. Still, none of them consider the car-following and lane-change behaviour of Autonomous Vehicles (AV) or pedestrian behaviour models which have an essential role in traffic. This paper presents an update on the existing CF and LC models with considerations of autonomous vehicles and pedestrian behaviours.

\section{CAR-FOLLOWING MODELS}

Car-following models describe the processes of vehicles following one another in the same lane. The space gap between vehicles significantly affects the traffic safety, capacity, and level of service. The car-following model is based on specific rules that update vehicle speed, the spatial position of the vehicle, and vehicle acceleration/deceleration over a selected period. The concept of car-following models was first proposed by Reuschel in 1950 and Pipes in 1953 [7, 8]. These models contained a safety parameter that stated that minimum bumperto-bumper distance is proportional to the speed. Using Laplace's transformation, Pipes developed a 
theoretical formulation for the acceleration of the follower vehicle with a mathematical function describing the behaviour of the leading vehicle. He assumed that the follower maintained a safe headway from the lead vehicle of 1.023 seconds [7].

\subsection{Gazis-Herman-Rothery/General motors model}

The Gazis - Herman - Rothery (GHR) model was developed in the General Motors Laboratory, Michigan, Detroit in the late 1950s and early 1960s. The GM model is based on determining the follower vehicle acceleration based on speed, relative speed, space gap, and driver reaction time. Through the years, several generations of the model were developed [9-13], and the final equation of the GHR/ GM model is as follows:

$$
\ddot{x}_{n+1}(t+T)=\frac{a \cdot \dot{x}_{n+1}^{m}(t+T) \cdot\left[\dot{x}_{n}(t)-\dot{x}_{n+1}(t)\right]}{\left[x_{n}(t)-x_{n+1}(t)\right]^{l}}
$$

where $x_{n}$ represents the position of $n$-th vehicle at time $t[\mathrm{~s}] ; T$ is the time lag from stimulus to response [s], and $m, l$, and $a$ are constants. To prove the above mathematical model, an experimental study was conducted using a vehicle equipped with wire. The car follower was equipped with a reel and a power unit mounted on a small platform which was fastened to the front bumper of the test car. The study showed no statistical correlation between the space gap and vehicle acceleration, while a significant statistical correlation was found between the changes in the vehicle speed and vehicle acceleration.

The linear model, also known as the Helly model [14], is an improvement to the GHR model in terms of adjusting the follower's acceleration in response to the leading vehicle deceleration. The simplified model is:

$$
\begin{aligned}
& a_{n}=C_{1} \Delta v(t-T)+C_{2}\left(\Delta x(t-T)-D_{n}(t)\right) \\
& D_{n}=\alpha+\beta v(t-T)+\gamma a_{n}(t-T)
\end{aligned}
$$

where $a_{n}$ is an acceleration of the $n$-th vehicle at time $t ; \Delta v$ is the relative speed between the vehicles; $\Delta x$ is the relative spacing between the vehicles; $T$ is the driver's reaction time; $D_{n}$ is the desired following distance $C_{1}, C_{2} ; \alpha, \beta, \gamma$ are model parameters.

Xing [15] developed a model based on a combination of the linear model and the GHR model.

The optimal velocity model was introduced by Newell [16] and was developed by Bando et al. [17]. The model assumes that drivers accelerate/ decelerate to their optimal speed, and the optimal speed is the function of headway. The acceleration/ deceleration is calculated by:

$\ddot{x}_{n}=a_{n}\left\{V\left(\Delta x_{n}\right)-\dot{x}_{n}\right\}$

where $x_{n}$ represents the position of $n$-th vehicle; $a_{n}$ is a constant representing the driver's sensitivity; and $\Delta x_{n}=x_{n+1}-x_{n}$ is the headway between the lead vehicle and the follower.

Treiber et al. [18] developed an Intelligent Driver Model (IDM) which consists of two parts (i) comparing current speed $v$ to the desired speed $v_{0}$, and (ii) comparing the current distance $s$ to the desired distance $s^{*}$. Mathematical descriptions of the IDM model are presented:

$$
\begin{aligned}
& \dot{v}=a\left[1-\left(\frac{v}{v_{0}}\right)^{\delta}-\left(\frac{s^{*}(v, \Delta v)}{s}\right)^{2}\right] \\
& s^{*}(v, \Delta v)=s_{0}+\max \left(0, v T+\frac{v \Delta v}{2 \sqrt{a b}}\right)
\end{aligned}
$$

where $\delta$ is the acceleration exponent; $s_{0}$ is the minimum relative spacing between vehicles; $s$ is the relative spacing between vehicles; $s^{*}$ is the desired spacing between vehicles; $a$ is maximum acceleration; $b$ is the desired deceleration; $T$ is the desired time headway; $v$ is the current speed; and $v_{0}$ is the desired speed.

The model can be explained by three common situations: (i) when the driver accelerates from a standstill, the vehicle starts at maximum acceleration $a$, the acceleration decreases with increasing speed and reaches zero as the speed approaches the desired speed $v_{0}$. The acceleration exponent $\delta$ controls this reduction of acceleration; (ii) when following a leading vehicle, the distance gap is approximatively given by the safety distance $s_{0}+v T$; (iii) when approaching slower or stopped vehicles, the deceleration usually does not exceed the comfortable deceleration $b$ [19].

\subsection{Collision avoidance models}

Collision avoidance models are based on determining a safe headway when following a vehicle and adjusting the driver's behaviour to avoid a collision [20]. According to Kometani and Sasaki [21], a collision will occur if the space gap between two successive vehicles is less than the required safety distance.

Safety distance is calculated using the following equation:

$\Delta x(t-T)=\alpha v_{n-1}^{2}(t-T)+\beta_{l} v_{n}^{2}(t)+\beta v_{n}(t)+b_{0}$ 
where $v_{n}$ represents the speed of the follower vehicle $[\mathrm{m} / \mathrm{s}] ; v_{n-1}$ the speed of the leading vehicle $[\mathrm{m} / \mathrm{s}]$ at time $t ; \Delta x$ the relative spacing between the follower vehicle and the leading vehicle $[\mathrm{m}] ; T$ driver reaction time; and $\alpha, \beta, \beta_{l}, b_{0}$ calibration constants [22].

The best known collision avoidance model is the Gipps model [23]. The model is currently used in the AIMSUN modelling software. The Gipps model is based on the collision avoidance and consists of two restrictions of the follower vehicle. The speed of the follower must not exceed the desired speed. The acceleration of the follower vehicle increases initially as the vehicle reaches the desired speed and then drops to zero. At any moment, the following driver should leave enough safe distance in front so that in case the leading vehicle starts emergency braking, the follower has time to respond and decelerate to a stop behind the leading vehicle without a collision [23, 24].

These restrictions are represented by the following equation:

$\min \left\{\begin{array}{l}v_{n}+2.5 a_{n} T\left(1-\frac{v_{n}(t)}{V_{n}}\right)\left(0.025+\frac{v_{n}(t)}{V_{n}}\right)^{\frac{1}{2}} \\ b_{n} T+\left\{b_{n}^{2} T^{2}-b_{n}\left[2\left(x_{n-1}(t)-s_{n-1}-x_{n}(t)\right)-v_{n}(t) T-\frac{v_{n-1}^{2}(t)}{b}\right]\right\}^{\frac{1}{2}}\end{array}\right.$

where $a_{n}$ represents maximum acceleration that the vehicle seeks to achieve $\left[\mathrm{m} / \mathrm{s}^{2}\right] ; b_{n}$ the maximum braking force that the driver wants to achieve; $s_{n-1}$ the length of the leading vehicle [m]; $V_{n}$ the desired speed at which the follower vehicle wants to move $[\mathrm{m} / \mathrm{s}] ; v_{n}$ is the speed of vehicle $n$ at time $t$; $x_{n}(\mathrm{t})$ the position of the follower vehicle at time $t ; \hat{b}$ follower driver's estimate of $b_{n-1}$; and $T$ driver reaction time $[\mathrm{s}]$.

\subsection{Psychophysical models}

Psychophysical models assume that the drivers can estimate the speed of the leading vehicle and respond to safety distance changes. This model was introduced by Michaels [25] and Wiedemann [26], who consider that the drivers will only react if they perceive that they approach a vehicle in front. The relative speed is perceived through the changes in the visual angle of the lead vehicle. Visual angle can be calculated by:

$$
\theta_{n}(t)=2 \arctan \left(\frac{W}{2 S_{n}(t)}\right) \approx \frac{W}{S_{n}(t)}
$$

where $W$ is the width of the preceding vehicle; $S_{n}$ is the spacing between the preceding and the subject vehicles, measured from the front edge of the subject vehicle to the rear end of the preceding vehicle.

One of the best known psychophysical driver behaviour models is the Wiedemann model, which is used in VISSIM microsimulation software [27]. This model uses the perceptual thresholds for different regimes of the driving behaviour, and the regimes are based on the driver's perceptions and actions. There are four driving regimes: (i) free driving, (ii) approaching, (iii) following, and (iv) emergency. In each of the regimes, different acceleration function is calculated. In the "free driving" regime, the follower strives to achieve and keep its desired speed, "approaching" regime consists of adapting the follower speed to its leader's speed. While approaching, the driver decelerates to a safe distance, and at that point, the relative speed of two vehicles is zero. In the "following" regime, safety distance between two successive vehicles is constant, and in the "emergency" regime, if the safety distance between two successive vehicles falls below the desired safety distance, the driver decelerates with maximum deceleration. After exceeding the perceptual threshold of one regime, the driver returns the acceleration to the value of the acceleration function for the existing situation and maintains the new acceleration until the perception threshold is exceeded again [24].

Saifuzzaman and Zheng [28] consider human factors necessary in car-following modelling for a more realistic representation of the driving behaviour in complex driving situations. According to the authors, in typical and often complex driving situations, humans adopt strategies that are adequate rather than optimal, because of their incomplete knowledge or insufficient time to evaluate all possible alternatives. The model parameters related to human factors are unobservable and, therefore, difficult to calibrate and validate using the general traffic data (i.e. traffic volume), which often leads to the assumptions that these parameters are constant when modelling the car-following behaviour.

\subsection{Fuzzy logic models}

Fuzzy logic-based models define fuzzy sets to allow variations in the driver behaviour in traffic flow, instead of assigning the same reaction to all drivers. This makes it possible to describe the differences in the drivers' perception of the environment. 
The values of different driver's subjective perceptions are associated with fuzzy rules through certain probability functions. Kikuchi and Chakroborty [29] were the first to apply fuzzy logic to car-following models using the GHR model. The model can predict the acceleration/deceleration values of the follower concerning the action of the leading vehicle. The range of possible reactions is predicted and expressed by the fuzzy membership function. They used three parameters to define fuzzy rules as input: (i) distance between the follower and lead vehicle (relative spacing), (ii) speeds of follower and leading vehicle (relative speed), and (iii) leading vehicle's acceleration or deceleration. The model can predict the acceleration and deceleration of the follower based on the relative speed and acceleration of the leading vehicle. Several other fuzzy logic-based car-following models have been developed [30-32]. Hao et al. [33] developed a fuzzy logic-based multi-agent car-following model that was able to imitate human driver, and the classic stimulus-response framework of the CF model was expanded to a five-layer structure, perception - anticipation - inference - strategy - action, to capture the driver's decision process in the car-following situation. The model consists of a large number of parameters due to fuzzy set membership functions. Seven actual vehicle trajectories extracted from the NGSIM (Next Generation SIMulation) database were used as examples to evaluate the proposed approach. In the comparison of the simulated and actual data, the simulation matched the actual trajectory, and the tendencies of acceleration, velocity, and space headway between the simulated and the actual were similar, which proves that the model was stable. Bennajeh et al. [34] developed an intelligent anticipation car-following model based on a modified fuzzy logic approach to estimate the speed of the leading vehicle. To model human behaviour, fuzzy rules were applied, which allows modelling of driver behaviour. The results show that the simulated vehicle trajectories based on the new model correspond to the actual vehicle trajectories in terms of deviation and gap distance. Cubranic-Dobrodolac et al. [35] used four psychological tests to evaluate the driver behaviour (the Barratt Impulsiveness Scale (BIS-11), the Aggressive Driving Behaviour Questionnaire (ADBQ), the Manchester Driver Attitude Questionnaire (DAQ) and the Questionnaire for Self-assessment of Driving Ability). The model was developed using fuzzy logic. Based on the results obtained from the tests, the model could quantify the driver propensity for traffic accidents. The modelling process consists of testing different types of fuzzy interference systems to select the one that generates the minimum amount of error in the data description. The results showed that the combination of all four tests indicates the best results when it comes to evaluating driver behaviour.

\subsection{Neural network models}

Pomerleau $[36,37]$ applied neural networks to simulate autonomous vehicle movement, and Fix and Armstrong [38] used them to model driver behaviour in a simulation model. Neural network training data was collected from a driver operating a driving simulator, and the results showed that the model successfully replicated the driver's behaviour in the traffic flow. Dougherty et al. [39, 40] developed a car-following model that uses neural networks with a back-propagation algorithm. Panwai and Dia [41] developed a neural network car-following model using data on vehicle speeds and spacing. Khodayari et al. [42] developed an artificial neural network model to predict car-following behaviour in the traffic flow. Reaction delay was used as a human effects and used as input in the car-following model. Zhou et al. [43] used a recurrent neural network to model car-following behaviour and to predict traffic oscillations successfully. To train and test the proposed model, the authors used the NGSIM database. It was found that the Recurrent Neural Network (RNN)-based model has the ability to establish traffic oscillations and to recognize different drivers characteristics. The authors compared the proposed RNN-based model to the Intelligent Driver Model (IDM). The results have shown that RNN has more accurate results when it comes to predicting the trajectories of vehicles and predicting the aggressive, timid, and normal oscillations (oscillation caused by drivers). Hua [44] also proposed a car-following model based on an RNN, which could describe traffic congestion while the vehicles were moving in the traffic flow. The traffic flow was simulated by one-dimensional discrete cells, and each cell represents the average length of a vehicle (5 $\mathrm{m})$. The research was conducted using a full velocity difference car-following model. To optimize the relative spacing between two successive vehicles in the RNN model, vehicle position and velocity were used as input parameters. The results have shown that when the relative velocity of two successive 
vehicles is greater, traffic congestion is more likely to occur, and the recurrent neural network car-following model can acquire a smaller safe distance.

\subsection{Neuro-fuzzy models}

In recent years, it has become popular to use a combination of fuzzy logic and neural networks when developing the car-following models. For example, Khodayari et al. [45] used Locally Linear Neuro-Fuzzy (LLNF) model to simulate and predict future driver behaviour. Local Linear Model Tree (LOLIMOT) learning algorithm is applied to train the model using real traffic data (NGSIM database). The results showed that the LLNF model based on instantaneous reaction delay input outperformed the other car-following models. Zarringhalam and Ghaffari [46] used Emotional Learning Fuzzy Inference System (ELFIS) to simulate and predict the future behaviour of a driver. The velocity of the follower and the relative distance between two successive vehicles are predicted. The algorithm is used to generate a warning message while a safe-distance keeping measure is violated in order to prevent a collision. The proposed method can be applied, in real-time, for a variety of applications, including driver assistant and collision prevention systems as well as other intelligent transportation applications. Wang et al. [47] proposed a car-following model with consideration of the driver's behaviour based on an Adaptive Neuro-Fuzzy Inference System (ANFIS). The ANFIS model fits the car-following data better than the traditional GM model because the ANFIS model can better capture the fuzzy, uncertain, and asymmetric behaviour of the drivers.

\subsection{Autonomous vehicles}

In recent years, many types of research have been conducted on the impact of autonomous vehicles on increasing road capacity and to investigate driver behaviour in a heterogeneous traffic flow consisting of human drivers and autonomous vehicles (HVs and AVs). Autonomous vehicles are equipped with cameras, infrared sensors, radars and GPS to capture information from the real-world. When exploring AVs, the authors mainly use microsimulation software to simulate their behaviour, and those simulations are based on the assumptions regarding the behaviour of autonomous vehicles. Zheng et al. [48] proposed a stochastic model for mixed traffic flow with Human-driven Vehicles (HVs) and Auto- mated Vehicles (AVs). The Lagrangian coordinates system was used to formulate the heterogeneous character of human drivers. The proposed model is qualified to investigate the interaction between AVs and HVs considering the uncertainty of human driving behaviour. The results show that AVs have a significant impact on the uncertainty and stability of the mixed traffic flow system. Larger AV penetration rates can reduce the uncertainty inherent in $\mathrm{HV}$ behaviour and improve the stability of the mixed flow substantially. Li et al. [49] conducted research to explore the impacts of mixed flow conditions (AVs and HVs). They proposed a theoretical model which could be able to increase road capacity with suitable right-of-way reallocation. The different AV rates and traffic demands are used, and different reallocations strategies are compared using SUMO simulation tools. To simulate the driver behaviour, the Gipps car-following model was used. The results show that road capacity on a two-lane road can be significantly improved with appropriate right-ofway reallocation strategies at low or medium AV rates, compared with the do-nothing right-of-way strategy. Zeidler et al. [50] analysed data of two autonomous vehicles driven in the real world and compared their car-following behaviour to simulations based on the Wiedemann car-following model. The standstill distances and the headway of autonomous vehicles were derived from the data. The simulations show that the behaviour of autonomous vehicles communicating with the leading vehicle is reproduced well in PTV VISSIM microsimulation software. Problems occur when simulating autonomous vehicles that do not communicate with their leader. Not too many proposed models are incorporated in the microsimulation tools.

\section{Summary: Car-following models}

The GM model is the most studied model whose parameters can be easily estimated. However, the lack of GM models is manifested in the inability to distinguish situations with large and small relative distances between vehicles in car-following mode. Other disadvantages of this model are in the use of the same value of reaction time for all drivers. The Optimal Velocity Model (OVM) depends on the space between the two successive vehicles. The lack of the model is evident in the production of unrealistic values of acceleration and deceleration. The reason is that the optimal velocity depends on the relative space gap between two successive vehicles, so that traffic density plays an essential role in 
this model. The lack of an Intelligent Driver Model (IDM) is that it does not consider the reaction time of the drivers. Gipps model is one of the wellknown and used models for simulating driver behaviour. The main disadvantage of the model is that there is no difference between the maximum and the desired deceleration while modelling the car-following mode. The same reaction time is applied to all drivers. Psychophysical models are based on determining the driver's perceptual thresholds on specific stimuli. The advantage of these models is that they take into account different behaviours of drivers in the traffic flow. The calibration of this

Table 1 - Summary of existing car-following models model is challenging due to determining the perceptual thresholds of all the drivers observed in the model. Fuzzy logic-based models allow variations in the driver behaviour in the traffic flow, instead of assigning the same parameter values to all drivers. However, the most significant disadvantage of these models is defining fuzzy rules in the same order as the driver himself. Neural network models can obtain better model results due to the adaptive structure of the network. The lack of using neural networks when simulating the car-following models is manifested in the wrong determination of the amount and type of data for neural network training.

\begin{tabular}{|c|c|c|c|}
\hline \multicolumn{2}{|c|}{ Car-following models } & Related literature & Model specifics \\
\hline \multirow{8}{*}{$\begin{array}{l}\text { Mathematical } \\
\text { models }\end{array}$} & \multirow{4}{*}{$\begin{array}{l}\text { GHR/General } \\
\text { Motors }\end{array}$} & $\begin{array}{l}\text { GHR model/GM models (1959) } \\
\text { [9] }\end{array}$ & \multirow{4}{*}{$\begin{array}{l}\text { The response of the following vehicle is related to } \\
\text { the stimulus of the leader vehicle and response is } \\
\text { the acceleration of the following vehicle }\end{array}$} \\
\hline & & Linear model; Helly (1959) [14] & \\
\hline & & $\begin{array}{l}\text { Optimal velocity; Newell (1963) } \\
\text { [16] }\end{array}$ & \\
\hline & & IDM; Treiber et al. (2000) [18] & \\
\hline & \multirow{3}{*}{$\begin{array}{l}\text { Collision } \\
\text { avoidance }\end{array}$} & Pipes (1953) [7] & \multirow{3}{*}{$\begin{array}{l}\text { A vehicle travelling at a safe speed would be able to } \\
\text { maintain a safe speed and distance indefinitely }\end{array}$} \\
\hline & & Kometani and Sasaki (1959) [21] & \\
\hline & & Gipps (1981) [23] & \\
\hline & Psychophysical & $\begin{array}{l}\text { Michaels (1963) [25] } \\
\text { Wiedmann (1974) [26] }\end{array}$ & $\begin{array}{l}\text { Perceptual thresholds (the function of speed } \\
\text { difference and spacing between lead and follower) }\end{array}$ \\
\hline \multirow{5}{*}{\multicolumn{2}{|c|}{ Fuzzy logic }} & $\begin{array}{l}\text { Kikuchi and Chakroborty (1992) } \\
\text { [29] }\end{array}$ & \multirow{5}{*}{$\begin{array}{l}\text { Fuzzy logic incorporates driving strategies for vari- } \\
\text { ous driving regimes into a set of simple fuzzy rules }\end{array}$} \\
\hline & & Gao et al. (2008) [30] & \\
\hline & & Hao et al. (2016) [33] & \\
\hline & & Bennajeh et al. (2018) [34] & \\
\hline & & $\begin{array}{l}\text { Cubranic-Dobrodolac et al. (2020) } \\
\text { [35] }\end{array}$ & \\
\hline \multirow{7}{*}{\multicolumn{2}{|c|}{ Neural network }} & Pomerleau $(1992)[36,37]$ & \multirow{7}{*}{$\begin{array}{l}\text { Neural network model can obtain better model re- } \\
\text { sults, but no precise mathematical formulation that } \\
\text { defines the relation between input variables and the } \\
\text { output variable is known }\end{array}$} \\
\hline & & Fix and Armstrong (1990) [38] & \\
\hline & & Dougherty et al. (1993) $[39,40]$ & \\
\hline & & Panwai and Dia (2007) [41] & \\
\hline & & Khodayari et al. (2012) [42] & \\
\hline & & Zhou et al. (2017) [43] & \\
\hline & & Hua (2019) [44] & \\
\hline \multirow{3}{*}{\multicolumn{2}{|c|}{ Neuro-fuzzy systems }} & Khodayari et al. (2011) [45] & \multirow{3}{*}{$\begin{array}{l}\text { Neuro-fuzzy system is a combination of neural } \\
\text { networks and fuzzy logic which uses membership } \\
\text { input and output functions and fuzzy rules in the } \\
\text { neural network }\end{array}$} \\
\hline & & $\begin{array}{l}\text { Zarringhalam and Ghaffari (2013) } \\
\text { [46] }\end{array}$ & \\
\hline & & Wang et al. (2015) [47] & \\
\hline \multirow{3}{*}{\multicolumn{2}{|c|}{ Autonomous vehicles }} & Zheng et al. (2020) [48] & \multirow{3}{*}{$\begin{array}{l}\text { Autonomous vehicles can be modelled by adjusting } \\
\text { acceleration/deceleration parameters, relative spac- } \\
\text { ing between vehicles, and standstill distances }\end{array}$} \\
\hline & & Li et al. (2020) [49] & \\
\hline & & Zeidler et al. (2018) [50] & \\
\hline
\end{tabular}




\section{LANE-CHANGING MODELS}

Lane change is one of the basic vehicle movements with a significant impact on traffic flow and safety. Changing the lane causes changes in vehicle speed, oscillations in traffic flow, and the occurrence of shock waves. According to [4], lane-changing models are divided into driving assistance and driving decision models with the corresponding sub models. Driving assistance models can be further divided into collision prevention models and automation models. The primary purpose of a collision prevention model is to assist the driver in changing lanes and to increase road safety. Automation models are used to adjust the steering wheel when changing lanes partially or entirely [51]. Driving decision models are based on performing lane changes due to different traffic situations and different traffic flow conditions. These models are integrated into various microsimulation tools. According to [52], driving decisions in the traffic flow are divided into three levels: (i) strategic, (ii) tactical, and (iii) operational. This classification is based on the time required to complete each action. The decision to change the lane cannot be planned and made in advance because the conditions of the traffic flow cannot be predicted, so that it can be categorized as tactical or operational. During tactical lane changes, drivers make decisions based on the current state of traffic flow and the anticipated future state of traffic flow. During operational lane changes, drivers make decisions based only on the current information and state of traffic flow.

According to [4], the driving decision models can be classified into models based on a search algorithm and models based on traffic characteristics. In the models based on the search algorithm, performing a lane change is a product of a tactical and operational decision. Tactical decision is the result of the above algorithm, while the operational decision is based on the traffic flow features and conditions.

\subsection{Models based on search algorithm}

Schlenoff et al. [53] developed a framework consisting of multiple algorithms to predict the future position of a vehicle. The algorithm creates a set of possible future vehicle positions for each future vehicle manoeuvre (acceleration/deceleration, lane change), and allocates a cost to each manoeuvre. The cost represents the danger that the driver would be exposed to if they performed a specific driving manoeuvre. The cost is calculated based on the characteristics of the traffic flow, the influence of the surrounding vehicles and the distance from the fixed obstacles. The algorithm calculates the probability of performing a particular manoeuvre based on the total cost value. Webster et al. [54] developed a lane-changing decision model based on a forward search algorithm. This algorithm generates a branching scheme of sequential manoeuvres for each vehicle in a specific time step. A sequence of manoeuvres leading to the optimum outcome, that is, the minimum travel time, is selected. Webster compared this model to the Gipps model [55]. The results showed that the number of events in which the proposed lanechange model performed better than the Gipps lanechange model were greater.

\subsection{Mathematical models}

In this model category, the driver's tactical and operational lane-changing decision depends on the traffic conditions and traffic flow features. The tactical decision depends on the current and anticipated future traffic flow features, while the operational decision depends only on the current traffic flow features.

Gipps [55] developed a model that incorporates the decisions a driver must make when changing lanes. The Gipps model is integrated in AIMSUN microsimulation tool. The driver's decision is based on the answers to the following questions: (i) is it possible to change the lane, (ii) is it necessary to change the lane, and (iii) is it desirable to change the lane. The answers to these questions depend on the distance from the driver's exit point. The model was developed to be used in conjunction with the Gipps car-following model, which had several drawbacks (see Equation 3). The Gipps model is based on the assumption that the driver will change lanes if the gap between the vehicles is large enough and if the driver deems it safe to change lanes. The above assumption has several weaknesses in congested traffic conditions where sufficient and safe gaps rarely occur.

Wiedemann and Reiter [56] developed a theoretical lane-changing model to explain the driver's decision-making process when changing lanes influenced by the driver's perception of the traffic flow conditions. This model, as well as the car-following model, is based on the perceptual thresholds of the drivers and integrated in the VISSIM 
microsimulation tool. In this model, different drivers behave differently in the traffic flow, which is not the case in other models. These differences were examined while driving in the traffic flow by analysing how drivers perceive and estimate the behaviour of the surrounding traffic in the traffic flow, safety requirements, desired speed and maximum possible acceleration and deceleration. Hidas [57] developed a lane-changing model that takes into account the driver's courtesy during merging or lane-changing under congested and incident-affected traffic conditions. Lane change was classified as: (i) normal (unforced), (ii) forced, and (iii) cooperative lane change. During standard lane change, there is no visible change in the gap between the vehicles in motion. During a forced change, the space gap between the vehicles is reduced before changing lanes and then increased. The forced lane-changing is based on the driver's courtesy concept. The vehicle which wants to change lane sends a 'courtesy' request to subsequent vehicles in the target lane; the request is evaluated by each vehicle and it is either refused or accepted, depending on several factors such as the speed, position and driver type of the responding vehicle. When a vehicle provides courtesy to another vehicle, it reduces its acceleration to ensure that a free gap of sufficient length is created during the next few seconds for the lane-changing vehicle. During a cooperative lane change, as opposed to a forced lane change, the space gap increases before the lane change and then decreases.

\subsection{Discrete choice models}

Ahmed et al. [58] developed a probabilistic lane-changing model based on discrete choice. $\mathrm{He}$ developed a three-phase model: (i) consideration of lane change, (ii) selection of the target lane, and (iii) acceptance of sufficient space gap to change lanes. He also defined three categories of driving manoeuvres when changing lanes: (i) Mandatory Lane Change, MLC; (ii) Discretionary Lane Change, DLC; and (iii) Forced Merging, FM. The mathematical formula of this model consists of a probability function. The function determines the probability of performing a lane change. The probability that the driver will select one of the categories of driving manoeuvres at time $t$ is:

$$
\begin{aligned}
& P_{t}\left(L C \mid v_{n}\right)=\frac{1}{1+\exp \left(-X_{n}^{L C}(t) \beta^{L C}-\alpha^{L C} v_{n}\right)} \\
& L C=M L C, D L C, F M
\end{aligned}
$$

where $P_{t}\left(L C \mid v_{n}\right)$ represents the probability of executing MLC, DLC, and FM at time $t ; X_{n}^{L C}(t)$ the vector of the variable affecting the lane change; $\beta^{L C}$ parameter vector; $v_{n}$ is individual specific random term assumed to be distributed standard normal in the population; and $\alpha^{L C}$ a parameter of $v_{n}$.

For merging into an adjacent lane, a gap is acceptable only when both lead and lag gaps are acceptable. The critical gap for driver $n$ at time $t$ is assumed to have the following functional form:

$G_{n}^{c r, q}(t)=\exp \left(X_{n}^{g}(t) \beta^{g}+\alpha^{g} v_{n}+\varepsilon_{n}^{g}(t)\right)$

where $G_{n}^{c r, q}(t)$ is the critical gap for driver $n$ at time $t ; X_{n}^{g}(t)$ is the vector of explanatory variables affecting the critical gap; $g$ is the gap; $\beta^{g}$ is the corresponding vector of parameters; $\alpha^{g}$ is parameter of $v_{n}$ for $g ; \varepsilon_{n}^{g}(t)$ is a generic random term. Assuming that the critical gap lengths are log-normally distributed, the conditional probability of acceptance of a gap is given by:

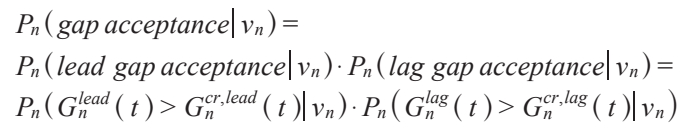

Toledo [59] developed an integrated probabilistic lane-changing decision model that allows the driver to consider MLC and DLC at the same time. He applied the laws of discrete choice to describe the driver's tactical and operational lane-changing decisions. The model was calibrated using the Maximum Likelihood Estimation, MLE. This model proposes a two-step lane-changing process: choice of the target lane and acceptance of the space and time gap. The utility of the lane change is described by the following equation:

$$
U_{n}^{\text {lane } i}(t)=X_{n}^{\text {lane } i}(t) \beta^{\text {lane } i}+\alpha^{\text {lane } i} v_{n}+\varepsilon_{n}^{\text {lane } i}(t)
$$

lane $i=C L, R L, L L$

where $U_{n}^{\text {lane } i}(t)$ represents the utility of lane $i$ to driver $n ; X_{n}^{\text {lane } i}$ the vector of the variable that affects the usefulness of lane $i$; $\beta^{\text {lane }} i$ parameter vector; $\varepsilon_{n}^{\text {lane } i}(t)$ random variable; $v_{n}$ is individual specific random term assumed to be distributed standard normal in the population; CL Current Lane; RL Right Lane; and LL Left Lane. The probability of selecting a lane is determined by the logistic model:

$$
P_{n}\left(\text { lane } i_{t} \mid v_{n}\right)=\frac{\exp \left[X_{n}^{\text {lane } i}(t)^{\text {lane } i}+v_{n}^{\text {lane } i}\right]}{\sum_{j \in I}\left[X_{n}^{\text {lane } i}(t)^{\text {lane } j}+v_{n}^{\text {lane } h}\right]}
$$

where lane $i$ and lane $j$ represent $I=\{\mathrm{CL}, \mathrm{RL}, \mathrm{LL}\}$; $X_{n}^{\text {lane } i}$ the vector of the variable that affects the usefulness of the lane; and $v_{n}^{\text {lane } i}$ random variable. 
The disadvantage of this model is the demanding process of determining the utility function for different driving decisions.

\subsection{New approaches to lane-change modelling}

Das et al. [60] developed a fuzzy logic-based microscopic simulation model called Autonomous Agent SIMulation Package (AASIM). Das et al. classified lane changes as: (i) Mandatory Lane Changes (MLC), and (ii) Discretionary Lane Changes (DLC). To determine when a Mandatory Lane Change (MLC) takes place, fuzzy logic takes into account the distance to the entrance or exit ramp and the number of lane changes that need to be made. Discretionary Lane Change (DLC) is based on the binary decision diagrams (change lane (1), or not change lane (0)) that are affected by the desired driver speed and the level of congestion in the left or right lane. The authors compared the results of the AASIM and CORSIM microsimulation models to the actual observed field data. They compared the traffic volume and the average speed on the weaving section of the road. The results showed that the difference in the average speed between AASIM and the actual data was $4.8[\mathrm{~km} / \mathrm{h}]$, while that between the CORSIM microsimulation tool and actual data was $16.0[\mathrm{~km} / \mathrm{h}]$. Moridpour et al. [61] developed fuzzy logic lane-changing decision model for heavy vehicle drivers on motorways. Two models were proposed; lane-changing to a slower lane (LCSL) and lane-changing to a faster lane (LCFL). The results showed that the LCFL model has a higher percentage, and the LCSL model has a lower percentage of accurately estimating the heavy vehicle driver's lane-changing decision.

Hou et al. [62] proposed a fuzzy logic-based lane-changing model for mandatory lane changes at lane closing. The genetic algorithm was used for optimizing the membership functions. The inputs to the fuzzy model were the speed of the merging vehicle, the relative speed between two successive vehicles, the relative speed between the lag vehicle and the merging vehicle, the lead gap distance, lag gap distance, and the remaining distance to the end of the merge lane. The fuzzy logic model was compared with the Logit model in terms of predicting the merge and non-merge events. The results showed that the fuzzy logic model is more accurate than the logit model in the lane-changing model. Balal et al. [63] proposed the Fuzzy
Inference System (FIS), which models the driver's binary decision to or not to ( 1 or 0$)$ execute a discretionary lane-changing move on the freeways. The four input variables were used in the model: the gap between the subject vehicle and the preceding vehicle in the original lane, the gap between the subject vehicle and the preceding vehicle in the target lane, the gap between the subject vehicle and the following vehicle in the target lane, and the distance between the preceding and the following vehicles in the target lanes. The authors compared FIS results with the existing TRANSMODELER's gap acceptance model, and the results have shown that the FIS has much better accuracy. Hunt and Lyons used artificial neural networks to predict lane changes on motorways [64]. The training data for neural networks were collected using an interactive driving simulator. The trained neural network successfully mastered the basic driving manoeuvres. Dumbuya et al. [65] developed neural driver agents (NDA), a multi-layered model that uses a back-propagation training algorithm. The input data used to develop the model were: current driving direction, current speed, space gap between two vehicles, desired speed, and the current traffic lane in which the vehicle is positioned. Based on the input data, output data such as the new driving direction and the desired vehicle speed were calculated. The NDA model used the vehicle trajectories collected from a driving simulator. Ding et al. [66] proposed the back-propagation (BP) neural network lane-changing model for trajectory prediction and compared the BP neural network model with the Elman Network. The BP neural network model showed better accuracy for predicting lane-changing trajectories under different path sections and generated reliable simulation results. Gao et al. [67] used three types of physiological signals from the driver to predict lane changes before the lane change occurs: electrocardiogram (ECG), Galvanic Skin Response (GSR), and Respiration Rate (RR). The model was developed by using a deep neural network. Tang et al. [68] used a combination of fuzzy logic and deep neural network to predict lane-change behaviour. The authors proposed a lane-changing prediction model based on the fuzzy clustering algorithm and adaptive neural network (FCMNN). Several input variables were used (relative spacing between vehicles, relative velocity between vehicles, movement direction, and acceleration) and one output variable (steering wheel angles). Three statistical indicators 
were used to evaluate the prediction performance: Mean Absolute Error (MAE), Mean Absolute Percentage Error (MAPE) and the Root Mean Square Error (RMSE). The prediction results indicate the effectiveness and stability of the proposed model. Zhang et al. [69] used deep learning to model the integrated car-following and lane-change behaviour.

Several studies used game-theory approach to model the lane-changing behaviour (Kita et al. [70], Wang et al. [71], Ali et al. [72]). The game theory is based on the interaction between the drivers (or agents), and the drivers can choose either to cooperate or not, to maximize their utility. More of the game theory can be found in Ji and Levinson [73].

Regarding cellular automata lane-change models, these models consists of four components: the environment, the cell states, the cell neighbourhoods, and the transition rules. The physical environment of applying cellular automata for traffic flow modelling is in the road segment of interest, which consists of a one-dimensional grid for a single-lane road. The grid and the time are discretized into equal-length cells typically equal to the vehicle length and the driver's average reaction time, respectively. This model is based on desirability and necessity of lane change and gap acceptance. Liu and Shi [74] combined cellular automata and neural networks to develop the traffic flow model for the lane-change decision. More about the cellular automata models can be found in Zheng [6].

Recently, many types of studies have been conducted to model the autonomous and connected vehicles lane-change behaviour. Lane change is a vital component of autonomous and connected driving behaviour. Choi and Yeo [75] proposed a framework for simulation-based lane-change control for autonomous vehicles. The authors used the lane-specific cell transmission to model and predict the future traffic flow and a genetic algorithm to optimize the total time delay function. Cao et al. [76] proposed a model to execute mandatory lane change of autonomous vehicles. The optimization model consists of determining the position at which an automotive navigation system should instruct AV. The model was validated using the VISSIM simulation software. The results showed that the model could determine the optimal position for the lane change and accurate estimate average travel time in the lane before the instruction to change the lane occurs. Rahman et al. [77] conducted safety impact of connected vehicles and connected vehicles with the lower level of automation features under Vehicle-to-Vehicle (V2V) and Infrastructure-to-Vehicle (I2V) communication technologies. The authors incorporated the IDM model to VISSIM simulation software to model the car-following and lane-change behaviour of the connected vehicles. Hu and Sun [78] proposed an algorithm for multilane freeway merging by optimizing lane change and car-following trajectories in the connected environment. Vechione et al. [79] compared a mandatory and discretionary lane-change behaviour on freeways using NGSIM database and model in AIMSUN microscopic software. The results suggested that the authors should develop MLC and DLC separately when modelling the lane-change behaviour. The above statement is especially evident in modelling the autonomous and connected vehicles.

\section{Summary: Lane-changing models}

The Gipps model imposes some limitations on the driver's braking rate to have a safe speed with respect to the preceding vehicle. The disadvantages of this model were related to the deceleration values for the follower vehicle; i.e. there is no difference between the maximum and the desired deceleration; only one value is applied. The same applies to the drivers' reaction time. Like car-following models, the psychophysical lane-change model is based on determining the perceptual thresholds of each driver in the network. The advantage of these models is evident in capturing different driver behaviours in the lane-change process. Still, the main disadvantage is calibrating these models and determining the perceptual thresholds accurately. Discrete models use a logit or probit model to model the decision to change lanes. In each phase, the utility for all alternatives in the process of changing lanes is calculated. The disadvantage of these models is that they do not consider the different characteristics of the driver behaviour in the traffic flow when deciding to change lanes. Fuzzy logic-based lane-changing models consider different driver behaviour in the traffic flow using fuzzy rules and fuzzy sets. The main disadvantage of these lane-change models is the same as for the car-following models. Neural network models have the training and testing phases, and this type of model can obtain better results, but it is not known what is happening in the background. The main disadvantage of these lanechange models is the same as for the car-following models. Regarding the game theory lane-changing models, this type of model is not frequently 
reviewed. The main disadvantage is evident in estimating the payoff function that tells us the payoff that each player (in this case each driver) gets as a function of the strategies chosen by all drivers. The lack of cellular automata lane-changing model is represented in the duration of lane-changing, usually as the length of the defined time step, which is no longer than $1 \mathrm{sec}$, which creates unrealistic observations and results.

\section{PEDESTRIAN BEHAVIOUR MODELS}

Compared to motorized driver behaviour models, non-motorized traffic has been much less studied in the traffic science. In recent years, increased awareness of the environmental issues and the needs of the residents for greater mobility have encouraged the decision-makers and transport professionals to better manage the pedestrian traffic. According to [80], the pedestrian flow research is divided

Table 2 - Summary of the existing lane-changing models

\begin{tabular}{|c|c|c|c|}
\hline \multicolumn{2}{|c|}{ Lane-change models } & Related literature & Model specifics \\
\hline \multirow{2}{*}{\multicolumn{2}{|c|}{ Search algorithm }} & Schlenoff et al. (2006) [53] & $\begin{array}{l}\text { The model uses multiple algorithms to predict future } \\
\text { vehicle position }\end{array}$ \\
\hline & & Webster et al. (2007) [54] & $\begin{array}{l}\text { Branching scheme is generated for each manoeuvre } \\
\text { that tries to find the minimum travel time }\end{array}$ \\
\hline \multirow{5}{*}{$\begin{array}{l}\text { Mathematical } \\
\text { models }\end{array}$} & \multirow[t]{2}{*}{ Stimulus-response } & Gipps (1986) [55] & $\begin{array}{l}\text { The model is based on the assumption that the driver } \\
\text { will change lanes if the gap between the vehicles is } \\
\text { large enough and if the driver deems it safe to change } \\
\text { lanes }\end{array}$ \\
\hline & & Hidas (2002) [57] & $\begin{array}{l}\text { This model is based on the drivers courtesy during } \\
\text { lane changing }\end{array}$ \\
\hline & Psychophysical & $\begin{array}{l}\text { Wiedemann and Reiter } \\
\text { (1992) [56] }\end{array}$ & $\begin{array}{l}\text { Perceptual thresholds (the function of speed } \\
\text { difference and spacing between lead and follower) }\end{array}$ \\
\hline & \multirow[b]{2}{*}{ Discrete } & Ahmed et al. (1996) [58] & \multirow{2}{*}{$\begin{array}{l}\text { The probability model is based on discrete theory. } \\
\text { Toledo developed integrated driving behaviour mod- } \\
\text { el that incorporates concepts of a short-term goal to } \\
\text { propose short-term plan }\end{array}$} \\
\hline & & Toledo (2002) [59] & \\
\hline \multirow{19}{*}{$\begin{array}{l}\text { New } \\
\text { approaches to } \\
\text { lane-change } \\
\text { modelling }\end{array}$} & \multirow{4}{*}{ Fuzzy logic } & Das et al. (1999) [60] & \multirow{4}{*}{$\begin{array}{l}\text { Fuzzy logic incorporates driving strategies for vari- } \\
\text { ous driving regimes into a set of simple fuzzy rules }\end{array}$} \\
\hline & & Moridpour et al. (2012) [61] & \\
\hline & & Hou et al. (2012) [62] & \\
\hline & & Balal et al. (2016) [63] & \\
\hline & \multirow{6}{*}{ Neural network } & Hunt and Lyons (1994) [64] & \multirow{6}{*}{$\begin{array}{l}\text { The neural network model can obtain better model } \\
\text { results, but no precise mathematical formulation that } \\
\text { defines the relation between the input variables and } \\
\text { the output variable is known. The neural network } \\
\text { can change structure during the training and testing } \\
\text { procedure. Input parameters (speed, acceleration/ } \\
\text { deceleration) must be set to model driver behaviour. }\end{array}$} \\
\hline & & Dumbuya et al. (2009) [65] & \\
\hline & & Ding et al. (2013) [66] & \\
\hline & & Gao et al. (2018) [67] & \\
\hline & & Tang et al. (2019) [68] & \\
\hline & & Zhang et al. (2019) [69] & \\
\hline & \multirow{3}{*}{ Game theory } & Kita (1999) [70] & \multirow{3}{*}{$\begin{array}{l}\text { The drivers maximize their respective payoffs to } \\
\text { achieve better outcomes under specific strategies of } \\
\text { opponents }\end{array}$} \\
\hline & & Wang et al. (2015) [71] & \\
\hline & & Ali et al. (2019) [72] & \\
\hline & Cellular automata & Liu and Shi (2018) [74] & $\begin{array}{l}\text { The model consists of four components: environ- } \\
\text { ment, cell states, cell neighbourhoods, and local rules }\end{array}$ \\
\hline & \multirow{5}{*}{ Autonomous vehicles } & Choi and Yeo (2017) [75] & \multirow{5}{*}{$\begin{array}{l}\text { Autonomous lane-change behaviour is similar to } \\
\text { human driving lane change (strategic, tactical, } \\
\text { operational). AV uses cameras, LIDAR, and sensors } \\
\text { to obtain information from the environment. Some } \\
\text { authors used human driving trajectories data to make } \\
\text { the assumptions regarding AV lane-change behaviour }\end{array}$} \\
\hline & & Cao et al. (2017) [76] & \\
\hline & & Rahman et al. (2019) [77] & \\
\hline & & Hu and Sun (2019) [77] & \\
\hline & & Vechione et al. (2018) [79] & \\
\hline
\end{tabular}


into two categories with respective subcategories: (i) data collection, and (ii) pedestrian flow analysis. Data collection is subdivided into macroscopic data collection and pedestrian movement monitoring, while pedestrian flow analysis is subdivided into macroscopic analysis and microscopic analysis. This paper focuses on the microscopic pedestrian behaviour. Pedestrian behaviour models that use microscopic analysis can adopt a simulation approach or an analytical approach. The simulation-based analysis of pedestrian flows includes cellular models, physical force models and queuing network models. Cellular models are based on modelling pedestrians as entities in cells. Pedestrian traffic surfaces are represented as a grid and the pedestrians as circles occupying the grid surface. The second phase involves the assignment of speed based on the available space gap and the ability to advance through the network based on speed [81]. Gipps and Marksjö [82] developed a cost-benefit model. This model shows the pedestrian as a particle in a cell. The pedestrian surface is divided into $0.5 \mathrm{~m} 2 \times 0.5 \mathrm{~m} 2$ cells that can only be occupied by a single pedestrian. They introduced a cell scoring system based on pedestrian proximity. The scoring system is based on the repulsive effect of nearby pedestrians and the positive effect of approaching the destination of the journey. The disadvantage of this model is the development of a precise scoring system and the calibration of data based on that scoring system. Xu et al. [83] proposed an indoor pedestrian tracking algorithm to improve the localization of a WiFi-based system. The indoor environment was divided into a grid to detect environmental constraints. The tracking algorithm subdivides the indoor space into grid cells and computes the position probability of the cells over time.

The magnetic force model was developed by Okazaki and Matsushita [84]. This model is based on the Coulomb's law and the assumption that the pedestrians and various obstacles are positively charged particles, while their destinations are negatively charged particles that attract them. The movement of each pedestrian was simulated by attraction between positively and negatively charged particles. Avoiding collisions between pedestrians acts as an accelerating force, calculated by:

$a=V \cdot \cos a \cdot \tan \beta$

where $a$ represents pedestrian acceleration to adjust their trajectory and avoid collision with other pedestrian $\left[\mathrm{m} / \mathrm{s}^{2}\right] ; V$ pedestrian speed $[\mathrm{m} / \mathrm{s}] ; \alpha$ the angle between the pedestrian's desired path and the selected path; and $\beta$ the angle between the desired path and the area occupied by the pedestrian. The sum of the forces from journey destinations, obstacles and other pedestrians affects the observed pedestrians in the network and determines their speed of movement over a period of time. The average speed, density and flow of pedestrians vary depending on the current situation.

Helbing and Molnar [85] developed a social force model, one of the most prominent pedestrian behaviour models. The social force model is integrated in PTV VISSWALK simulation software for simulating the pedestrian behaviour and interaction between pedestrians and vehicles and pedestrians and public transport. The model consists of forces that propel pedestrians and maintain adequate distance from other pedestrians and obstacles. Individual pedestrian movement results from the sum of the forces acting on the pedestrian, including the pedestrian's movement force, other pedestrians' movement forces and the force of the fixed obstacles.

The change in pedestrian speed can be expressed by:

$m_{i} \frac{d v_{i}(t)}{d t}=f_{i}^{\text {elf }}+\sum_{j \neq i} f_{i j}+\sum_{w} f_{i w}+\xi_{i}$

where $m_{i}$ represents the mass of pedestrian $i[\mathrm{~kg}]$; $v_{i}$ current pedestrian speed; $\xi^{i}$ force deviations; $f_{i j}$ force between pedestrian $i$ and pedestrian $j$ interactions; and $f_{i w}$ force of the obstacles and walls affecting pedestrian $i$.

The force acting on the pedestrians and their movement can be expressed as:

$f_{i}^{\text {self }}=m_{i} \frac{v_{i}^{0}(t)-v_{i}(t)}{\tau_{i}}$

where $v_{i}^{0}$ represents the desired pedestrian speed $[\mathrm{m} / \mathrm{s}] ; v_{i}$ current pedestrian speed $[\mathrm{m} / \mathrm{s}]$; and $\tau_{i}$ the observed time period.

The desired pedestrian speed represents the speed that the pedestrian seeks to attain, while the current speed represents the speed at which the pedestrian actually moves [86].

Antonini et al. [87] proposed a discrete choice framework for pedestrian dynamics, modelling short-term behaviour of individuals as a response to the presence of other pedestrians. The authors developed a model which can predict the next step of the walking pedestrian. The model was calibrated using pedestrian movements from the video footage. 
The queuing network model [88] is used to simulate pedestrian behaviour during building evacuation. It is based on a Monte Carlo simulation where each room represents a node and the doors between the rooms represent links. Each pedestrian starts from one node, waits in line and reaches the next node. Pedestrians move from one node to another in search of an exit door. Each pedestrian tries to reach the exit as safely and quickly as possible. When a pedestrian reaches a node, they make a weighted-random choice to determine the next link to use on their route. The weight parameters depend on the density of pedestrians in the room. If the link cannot be used, the pedestrian will wait or find a new route.

\section{Summary: Pedestrian behaviour models}

In cellular-based models, the network is represented as a grid, and pedestrians are represented as entities in the cell. The advantage of these models is that they are simple and easy to use, and computation time is lower in comparison to other models. The lack of these models are represented in discretization effects (space is discretized into square or cell, and time in the time step) and wall penetration (when pedestrians move around a corner). Social Force Models (SFM) are the most used models when simulating pedestrian behaviour. The main limitation of SFM is evident when pedestrians approach an obstacle. In the model, the higher the pedestrian speed, the greater will be the repulsive force of the obstacle. In reality, the pedestrian is aware of the obstacle, and will slow down much earlier. Regarding discrete pedestrian models that are based on utility maximization, the main limitation of these models is evident in defining variables of the utility function and the number of alternatives, which significantly affect the computation time. The queuing network models are used in modelling the pedestrian dynamics during the building evacuation. Modelling of pedestrian dynamics during an evacuation is very challenging due to the large number of pedestrians involved in the process, psychological factors that influence the pedestrian behaviour, and layout of the facility.

\section{DISCUSSION}

In recent years, various car-following, lane-changing, and pedestrian behaviour models have been developed. These models are divided into several previously mentioned categories. Car-following models based on mathematical expressions derive their parameter estimations from a single value for each parameter not taking into account the variations in the driver behaviour. These parameters are related to speed, acceleration / deceleration, space gap, time interval, and driver reaction time. Most of these models were developed on the basis of data collected on motorways. To improve the existing models and develop new ones, it is necessary to collect and analyse data on driver behaviour in urban and rural areas (city avenues, streets, intersections, etc.). It is in these areas that variations in driver behaviour are most pronounced. Also, the geometry of the road (longitudinal grade, road lane width, etc.) was not taken into account when developing these models. Starting a vehicle uphill can be challenging for some drivers, and by this action, it takes longer to achieve the desired speed. The above applies especially to heavy goods vehicles when starting and driving uphill. From a driver's psychological view, wider road lanes allow higher desired speeds.

Table 3 - Summary of existing pedestrian behaviour models

\begin{tabular}{|c|c|c|c|}
\hline \multicolumn{2}{|c|}{ Pedestrian models } & Related literature & Model specifics \\
\hline \multirow{7}{*}{ Simulation } & \multirow{3}{*}{ Cellular-based } & Blue and Adler (1998) [81] & \multirow{3}{*}{$\begin{array}{l}\text { The network is represented as a grid, and pedestrians are } \\
\text { represented as entities in the cell }\end{array}$} \\
\hline & & Gipps and Marksjö (1985) [82] & \\
\hline & & $\mathrm{Xu}$ et al. (2018) [83] & \\
\hline & \multirow{2}{*}{$\begin{array}{l}\text { Physical } \\
\text { force-based }\end{array}$} & Okazaki and Matsushita (1993) [84] & \multirow{2}{*}{$\begin{array}{l}\text { The model consists of a forward force of pedestrian and } \\
\text { repulsive force from other pedestrians and obstacles }\end{array}$} \\
\hline & & Helbing and Molnar (1995) [85] & \\
\hline & Discrete & Antonini et al. (2006) [87] & $\begin{array}{l}\text { The model is based on utility maximization and num- } \\
\text { bers of alternatives }\end{array}$ \\
\hline & Queuing & Lovas (1994) [88] & $\begin{array}{l}\text { The models are used to simulate pedestrian behaviour } \\
\text { during evacuation, and each pedestrian is treated as a } \\
\text { separate flow object }\end{array}$ \\
\hline
\end{tabular}


Most car-following and lane-changing models have been developed by analysing passenger cars only. Some authors $[89,90]$ have compared the behaviour of heavy goods vehicle drivers and passenger cars, but without developing a separate model for heavy goods vehicle driver behaviour. Aghabayk et al. [91] developed a heavy goods vehicle-following model using local linear models. However, it has not been integrated into any microsimulation tools to be tested in different traffic situations.

When developing the driver and pedestrian behaviour models, the authors used the traffic flow data available to them, and the parameters obtained were derived from these data. To eliminate the possibility of misinterpreting the model results, different traffic flow conditions must be taken into account depending on the observed location and the type of traffic flow (homogeneity and heterogeneity of the traffic flow).

Microsimulation models must be properly calibrated before making evaluations or conclusions as driver behaviour varies significantly depending on the location (driver behaviour varies from one city, region, etc. to another). With inadequate model parameter calibration, it is impossible to obtain realistic data from the simulation model, which may lead to erroneous conclusions. It is imperative that the authors of new car-following and lane-changing models provide parameter calibration methodology to enable the model to be adjusted for local conditions. Among various ways of calibrating driver behaviour model parameters those that stand out are: (i) parameter calibration by analysing vehicle trajectories obtained from video data or GPS [92-95], and (ii) parameter calibration by analysing traffic flow data (speed, traffic volume, density, etc.) $[96,97]$. In recent years, the authors have used artificial intelligence to calibrate the model parameters. For example, Istoka-Otkovic used a neural network to calibrate the car-following model [98], and the genetic algorithm [99].

With more researches conducted to model pedestrian-vehicle conflicts and validate the models using simulation tools, it is crucial to dedicate more time and studies on the calibration of pedestrian-vehicle interaction. For example, Feliciani et al. [100] developed a simulation model for predicting pedestrian fatalities at unsignalised crosswalks.
Although a large number of driver and pedestrian behaviour models have been analysed, what is to be expected in the future is that models integrated into the most common simulation tools such as Vissim and Aimsun will be used more often. Primarily, the focus should be on upgrading them and calibrating specific parameters in different traffic flow conditions. In particular, today's technological capabilities make it possible to test different patterns of driver and pedestrian behaviour in laboratory conditions using a driving simulator.

Although there has been some research conducted on modelling AV behaviour, additional research needs to be undertaken to develop autonomous vehicle models and integrate them into the existing simulation tools.

Driving and pedestrian behaviour models are used in the area of traffic safety. Safety surrogate measures [101] are commonly used to analyse potential vehicle and pedestrian conflicts by extracting trajectories of each entity. To examine the potential conflicts, the authors should use one of many existing behaviour models, accurately calibrate the specific parameters to local conditions, extract trajectories, and evaluate the results.

\section{CONCLUSION}

The main goal of this paper was to analyse the existing car-following, lane-changing, and pedestrian behaviour models, and to highlight the importance of applying accurately calibrated models in the simulation tools. An overview of the historical development of these models, their stratification, and the advantages and disadvantages have been given. The contribution of this review paper is in updating the existing review papers regarding car-following and lane-changing models and further analysis of their application in the field of autonomous vehicles and pedestrian behaviour.

KARLO BABOJELIĆ, mag. ing. traff. ${ }^{1}$

E-mail: kbabojelic@fpz.unizg.hr

Doc. dr. sc. LUKA NOVAČKO ${ }^{1}$

E-mail: luka.novacko@fpz.unizg.hr

Sveučilište u Zagrebu, Fakultet prometnih znanosti

Vukelićeva 4, 10000 Zagreb, Hrvatska

\section{MODELIRANJE PONAŠANJA VOZAČA I PJEŠAKA - POVIJESNI PREGLED}

Ponašanje vozača i pješaka značajno utječe na sigurnost prometa i prometni tok na mikroskopskoj i makroskopskoj razini. Modeli ponašanja vozača opisuju 
vozačeve odluke donesene u različitim uvjetima prometnoga toka. Modeliranje ponašanja pješaka ima ključnu ulogu u analizi pješačkih tokova u područjima kao što su: putnički terminali, pješačke zone, evakuacije i slično. Modeli ponašanja vozača, integrirani u simulacijske alate, mogu biti podijeljeni u modele slijeđenje vozila $i$ modele promjene prometnog traka. Simulacijski se alati koriste za oponašanje stvarnih prometnih tokova te donošenje zaključaka o pojedinim zakonitostima u njima. Pojedinačni parametri modela moraju biti adekvatno kalibrirani kako bi opisivali stvarne uvjete prometnoga toka. Ovaj rad opisuje postojeće modele slijeđenja vozila, modele promjene prometnoga traka i modele ponašanja pješaka. Nadalje, naglašava važnost kalibracije parametara mikrosimulacijskih modela kako bi replicirali realne uvjete prometnog toka te postavlja smjernice buducih istraživanja, a koji se odnose na razvoj novih modela te poboljšanje postojećih.

\section{KLJUČNE RIJEČI}

modeli ponašanja vozača i pješaka; slijeđenje vozila; promjena prometnoga traka; kalibracija;

\section{REFERENCES}

[1] Brackstone M, McDonald M. Car-following: A historical review. Transportation Research Part F: Traffic Psychology and Behaviour. 1999;2: 181-196. Available from: doi:10.1016/S1369-8478(00)00005-X [Accessed $9^{\text {th }}$ March 2019].

[2] Toledo T. Driving Behaviour: Models and Challenges. Transport Reviews. 2007;27:1: 65-84. Available from: doi:10.1080/01441640600823940 [Accessed 3 ${ }^{\text {rd }}$ March 2019].

[3] Aghabayk K, Sarvi M, Young W. A State-of-the-Art Review of Car-Following Models with Particular Considerations of Heavy Vehicles. Transport Reviews: A Transnational Transdisciplinary Journal. 2015;35(1): 82-105. Available from: doi:10.1080/01441647.2014.9 97323 [Accessed ${ }^{2 \text { nd }}$ March 2019].

[4] Moridpour S, Sarvi M, Rose G. Lane changing models: A critical review. Transportation Letters: The International Journal of Transportation Research. 2010;2: 57173.

[5] Rahman M, Chowdhury M, Xie Y, He Y. Review of Microscopic Lane-Changing Models and Future Research Opportunities. IEEE Transactions on Intelligent Transportation Systems. 2013;14(4): 1942-1956. Available from: doi:10.1109/TITS.2013.2272074 [Accessed 21 th March 2019].

[6] Zheng Z. Recent developments and research needs in modelling lane changing. Transportation Research Part B: Methodological. 2014;60: 16-32. Available from: doi:10.1016/j.trb.2013.11.009 [Accessed 15 th $^{\text {th }}$ May 2020].

[7] Pipes LA. An operational analysis of traffic dynamics. Journal of Applied Physics. 1953;24: 274-281.

[8] Reuschel A. Fahrzeugbewegungen in der Kolonne.
Österreichisches Ingenieur-Archiv. 1950;4: 193-215.

[9] Chandler RE, Herman R, Montroll EW. Traffic dynamics: Studies in car following. Operations Research. 1959;6: 165-184.

[10] Herman R, Montroll EW, Potts RB, Rothery RW. Traffic dynamics: Analysis of stability in car following. $O p$ erations Research. 1959;7: 86-106.

[11] Gazis DC, Herman R, Potts RB. Car following theory of steady state traffic flow. Operations Research. 1959;7: 499-505.

[12] Gazis DC, Herman R, Rothery RW. Nonlinear follow the leader models of traffic flow. Operations Research. 1961;9: 545-567.

[13] Bevrani K, Chung E, Miska M. Evaluation of the GHR car following model for traffic safety studies. Proceedings of the $25^{\text {th }}$ ARRB Conference, ARRB Group Ltd, Perth, W. A., Australia; 2012. p. 1-11.

[14] Helly W. Simulation of Bottlenecks in Single Lane Traffic Flow. Proceedings of the Symposium on Theory of Traffic Flow. Research Laboratories, General Motors, New York: Elsevier; 1959. p. 207-238.

[15] Xing J. A parameter identification of a car following model. Proceedings of the Second World Congress on ATT. 9-11 Nov. 1995, Yokohama, Japan; 1995. p. 17391745.

[16] Newell GF. Instability in dense highway traffic: A review. Proceedings of the Second International Symposium on the Theory of Traffic Flow, London; 1963. p. 73-83.

[17] Bando M, Hasebe K, Nakayama A, Shibata A, Sugiyama Y. Dynamical model of traffic congestion and numerical simulation. Physical Review E. 1995;51(2): 1035-1042.

[18] Treiber M, Hennecke A, Helbing D. Congested traffic states in empirical observations and microscopic simulations. Physical Review. 2000;62(2): 1805-1824. Available from: https://journals.aps.org/pre/abstract/10.1103/ PhysRevE.62.1805 [Accessed 15th March 2019].

[19] Treiber M, Kesting M. Traffic Flow Dynamics: Data, Models and Simulation. $1^{\text {st }}$ ed. Springer-Verlag Berlin Heidelberg; 2013.

[20] Ciuffo B, Punzo V, Montanino M. Thirty Years of Gipps' Car-Following Model. Transportation Research Record Journal of the Transportation Research Board. 2012;2315: 89-99. Available from: doi:10.3141/231510 [Accessed 25th March 2019].

[21] Kometani E, Sasaki T. Dynamic behaviour of traffic with a nonlinear spacing-speed relationship. Proceedings of the Symposium on Theory of Traffic Flow. Research Laboratories, General Motors, New York: Elsevier; 1959. p. 105-119.

[22] Panwai S, Dia H. Comparative Evaluation of Microscopic Car-Following Behaviour. IEEE Transactions on Intelligent Transportation Systems. 2005;6(3): 314325. Available from: doi:10.1109/TITS.2005.853705 [Accessed 17th April 2019].

[23] Gipps PG. A behavioural car following model for computer simulation. Transportation Research Part B: Methodological. 1981;15(2): 105-111.

[24] Elefteriadou, L. An Introduction to Traffic Flow Theory. 
$1^{\text {st }}$ ed. Springer-Verlag Berlin Heidelberg; 2014.

[25] Michaels RM. Perceptual factors in car following. Proceedings of the $2^{\text {nd }}$ International Symposium on the Theory of Road Traffic Flow, London, England. OECD; 1963.

[26] Wiedemann R. Simulation des Strassenverkehrsflusses. Technical report, Institut für Verkehrswesen, Universität Karlsruhe, Karlsruhe, Germany; 1974. German.

[27] Yousif S, Al-Obaedi J. Close following behaviour: Testing visual angle car following models using various sets of data. Transportation Research Part F: Traffic Psychology and Behaviour. 2011;14(2): 96-110.

[28] Saifuzzaman M, Zheng Z. Incorporating human-factors in car-following models: A review of recent developments and research needs. Transportation Research Part C: Emerging Technologies. 2014;48: 379-403. Available from: doi:10.1016/j.trc.2014.09.008 [Accessed 9th April 2020].

[29] Kikuchi C, Chakroborty P. Car following model based on a fuzzy inference system. Transportation Research Record: Journal of the Transportation Research Board. 1992;1365: 82-91.

[30] Gao Q, Hu S, Dong C. The Modelling and Simulation of the Car-following Behaviour Based on Fuzzy Inference. International Workshop on Modelling, Simulation and Optimization, Hong Kong; 2008. p. 322-325. Available from: doi:10.1109/WMSO.2008.48 [Accessed $29^{\text {th }}$ March 2019].

[31] Won J, Lee S, Lee S, Kim T. Establishment of Car Following Theory Based on Fuzzy-Based Sensitivity Parameters. In: Cham T-J, Cai J, Dorai C, Rajan D, Chua T-S, Chia L-T. (eds.) Proceedings of the $13^{\text {th }}$ International Multimedia Modelling Conference, MMM 2007, 9-12 January, 2007, Singapore. Lecture Notes in Computer Science, vol. 4352. Springer, Berlin, Heidelberg; 2007.

[32] Zheng P, McDonald M. Application of fuzzy systems in the car-following behaviour analysis. Proceedings of the $2^{\text {nd }}$ International Conference on Fuzzy Systems and Knowledge Discovery, Changsha, China. Vol. 3613; 2005. p. 782-791.

[33] Hao H, Ma W, Xu H. A fuzzy logic-based multi-agent car-following model. Transportation Research Part C: Emerging Technologies. 2016;69: 477-496. Available from: doi:10.1016/j.trc.2015.09.014. [Accessed $5^{\text {th }}$ May 2020].

[34] Bennajeh A, Bechikh S, Ben Said L, Aknine S. A Fuzzy Logic-Based Anticipation Car-Following Model. In: Nguyen NT, Kowalczyk R. (eds.) Transactions on Computational Collective Intelligence $X X X$. Springer International Publishing; 2018. p. 200-222.

[35] Cubranic-Dobrodolac M, Svadlenka L, Cicevic S, Dobrodolac M. Modelling driver propensity for traffic accidents: A comparison of multiple regression analysis and fuzzy approach. International Journal of Injury Control and Safety Promotion. 2020;27(2): 156-167. Available from: doi:10.1080/17457300.2019.1690002 [Accessed $17^{\text {th }}$ April 2020].

[36] Pomerleau DA. ALVINN: An autonomous land vehicle in a neural network. In: Touretzky DS. (ed.) Advances in Neural Information Processing Systems 1. San Mateo, CA: Morgan Kaufmann; 1989. p. 305-313.

[37] Pomerleau DA. Progress in neural network-based vision for autonomous robot driving. Proceedings of the Intelligent Vehicle Symposium, Detroit, MI. 1992. p. 391-396.

[38] Fix E, Armstrong HG. Modelling human performance with neural networks. Proceedings of the International Joint Conference on Neural Networks, San Diego, CA; 1990. p. 247-252.

[39] Dougherty MS, Kirby HR, Boyle RD. The use of neural networks to recognise and predict traffic congestion. Traffic Engineering and Control. 1993;34(6): 311-314.

[40] Dougherty M. A review of neural networks applied to transport. Transportation Research Part C: Emerging Technologies.1995;3(4): 247-260.

[41] Panwai S, Dia H. Neural agent car-following models. IEEE Transactions on Intelligent Transportation Systems. 2007;8(1): 60-70.

[42] Khodayari A, Ghaffari A, Kazemi R, Braunstingl R. A Modified Car-Following Model Based on a Neural Network Model of the Human Driver Effects. IEEE Transactions on Systems, Man, and Cybernetics - Part A: Systems and Humans. 2012;42(6): 1440-1449. Available from: doi:10.1109/TSMCA.2012.2192262 [Accessed $1^{\text {st }}$ June 2020].

[43] Zhou M, Qu X, Li X. A recurrent neural network based microscopic car following model to predict traffic oscillation. Transportation Research Part C: Emerging Technologies. 2017;84: 245-264. Available from: doi:10.1016/j.trc.2017.08.027 [Accessed 9 ${ }^{\text {st }}$ June 2020].

[44] Hua C. A new car-following model considering recurrent neural network. International Journal of Modern Physics B. 2019:33(26). Available from: doi:10.1142/ S0217979219503041 [Accessed $4^{\text {th }}$ May 2020].

[45] Khodayari A, Ghaffari A, Kazemi R, Braunstingl R. Modify Car Following Model by Human Effects Based on Locally Linear Neuro Fuzzy. IEEE Intelligent Vehicles Symposium (IV), 5-9 June 2011, Baden-Baden, Germany. 2011. p. 661-666. Available from: doi:10.1109/ IVS.2011.5940465

[46] Zarringhalam R, Ghaffari A. Collision Prevention While Driving in Real Traffic Flow Using Emotional Learning Fuzzy Inference Systems. SAE International Journal of Transportation Safety. 2013:1(1): 58-63. Available from: doi:10.4271/2013-01-0623 [Accessed $7^{\text {th }}$ June 2020].

[47] Wang J, Zhang L, Lu S, Wang Z. Developing a car-following model with consideration of driver's behaviour based on an Adaptive Neuro-Fuzzy Inference System. Journal of Intelligent \& Fuzzy Systems. 2015:30(1): 461-466. Available from: doi:10.3233/IFS-151770 [Accessed $10^{\text {th }}$ June 2020].

[48] Zheng F, Liu C, Liu X, Jabari SE, Lu L. Analyzing the impact of automated vehicles on uncertainty and stability of the mixed traffic flow. Transportation Research Part C: Emerging Technologies. 2020;112: 203-219. Available from: doi:10.1016/j.trc.2020.01.017 [Accessed $18^{\text {th }}$ June 2020] .

[49] Li T, Guo F, Krishnan R, Sivakumar A, Polak J. 
Right-of-way reallocation for mixed flow of autonomous vehicles and human driven vehicles. Transportation Research Part C: Emerging Technologies. 2020;115: 102630. Available from: doi:10.1016/j. trc.2020.102630 [Accessed 13 ${ }^{\text {th }}$ June 2020].

[50] Zeidler V, Buck HS, Kautzsch L, Vortisch P, Weyland CM. Simulation of autonomous vehicles based on Wiedemann's car following model in PTV Vissim. Transportation Research Board 98 $8^{\text {th }}$ Annual Meeting, 13-17 January 2019, Washington DC, United States; 2019.

[51] Mar J, Lin HT. The Car-following model and Lane-changing Collision Prevention System Based on the Cascaded Fuzzy Inference System. IEEE Transactions on Intelligent Transportation Systems. 2005;54(3): 910-924. Available from: doi:10.1109/ TVT.2005.844655 [Accessed 21 ${ }^{\text {th }}$ March 2019].

[52] Michon AJ. A critical view of driver behaviour models: What do we know, what should we do? In: Evans L, Schwing RC. (eds) Human Behaviour and Traffic Safety. Springer, Boston, MA; 1985. p. 485-520.

[53] Schlenoff C, Madhavan R, Kootbally Z. PRIDE: A hierarchical, integrated prediction framework for autonomous on-road driving. Proceedings of the 2006 IEEE International Conference on Robotics and Automation, ICRA 2006, Orlando, FL; 2006, p. 2348-2353. Available from: doi:10.1109/ROBOT.2006.1642053 [Accessed 28 ${ }^{\text {th }}$ March 2019].

[54] Webster NA, Suzuki T, Chung E, Kuwahara M. Tactical Driver Lane Change Model Using Forward Search. Proceedings of the $86^{\text {th }}$ Transportation Research Board Annual Meeting, Washington, DC; 2007. p. 1-22.

[55] Gipps PG. A Model for the Structure of Lane changing Decisions. Transportation Research Part B: Methodological. 1986;20(5): 403-414.

[56] Wiedemann R, Reiter U. Microscopic Traffic Simulation: the Simulation System Mission, Background and Actual State. CEC Project ICARUS (V1052), Final Report, vol. 2, Appendix A. Brussels: CEC; 1992.

[57] Hidas P. Modelling Lane Changing and Merging in Microscopic Traffic Simulation. Transportation Research Part C: Emerging Technologies. 2002;10(5-6): 351371.

[58] Ahmed KI, Ben-Akiva M, Koutsopoulos HN, Mishalani RG. Models of Freeway Lane Changing and Gap Acceptance Behaviour. Proceedings of the $13^{\text {th }}$ International Symposium on the Theory of Traffic Flow and Transportation, 24-26 July1996, Lyon, France; 1996. p. 501-515.

[59] Toledo T. Integrated driving behaviour modelling. $\mathrm{PhD}$ thesis. Massachusetts Institute of Technology; 2002.

[60] Das S, Bowles BA, Houghland CR, Hunn SJ, Zhang Y. Microscopic simulations of freeway traffic flow. Proceedings of the 32nd Annual Simulation Symposium, San Diego, CA, USA; 1999. p. 79-84. Available from: doi:10.1109/SIMSYM.1999.766457 [Accessed $3^{\text {rd }}$ April 2019].

[61] Moridpour S, Sarvi M, Rose G, Mazloumi E. Lane-changing decision model for heavy vehicle drivers. Journal of Intelligent Transportation Systems. 2012;16(1): 24-35. Available from: doi:10.1080/15472
450.2012.639640 [Accessed 13 ${ }^{\text {th }}$ June 2020].

[62] Hou Y, Edara P, Sun C. A genetic fuzzy system for modelling mandatory lane changing. $201215^{\text {th }}$ International IEEE Conference on Intelligent Transportation Systems, 16-19 September 2012, Anchorage, AK, United States. 2012.

[63] Balal E, Cheu RL, Sarkodie-Gyan T. A binary decision model for discretionary lane changing move based on fuzzy inference system. Transportation Research Part C: Emerging Technologies. 2016;67: 47-61. Available from: doi:10.1016/j.trc.2016.02.009 [Accessed 21 $1^{\text {th }}$ June 2020].

[64] Hunt JG, Lyons GD. Modelling dual carriageway lane-changing using neural networks. Transportation Research Part C: Emerging Technologies. 1994;2(4): 231-245.

[65] Dumbuya A, Booth A, Reed N, Kirkham A, Philpott T, Zhao J, Wood R. Complexity of traffic interactions: Improving behavioural intelligence in driving simulation scenarios. In: Bertelle C, Duchamp GH, Kadri-Dahmani H. (eds) Complex Systems and Selforganization Modelling. Understanding Complex Systems. New York, NY, USA: Springer-Verlag; 2009. p. 201-209.

[66] Ding C, Wang W, Wang X, Baumann M. A Neural Network Model for Driver's Lane-Changing Trajectory Prediction in Urban Traffic Flow. Mathematical Problems in Engineering; 2013. Available from: doi:10.1155/2013/967358 [Accessed 11 ${ }^{\text {th }}$ June 2020].

[67] Gao J, Murphey YL, Zhu H. Multivariate time series prediction of lane changing behaviour using deep neural network. Applied Intelligence. 2018;48: 3523-3537. Available from: doi:10.1007/s10489-018-1163-9 [Accessed $16^{\text {th }}$ June 2020].

[68] Tang J, Yu S, Liu F, Chen X, Huang H. A hierarchical prediction model for lane-changes based on combination of fuzzy C-means and adaptive neural network. Expert Systems with Applications. 2019;130: 265-275. Available from: doi:10.1016/j.eswa.2019.04.032 [Accessed $17^{\text {th }}$ June 2020].

[69] Zhang X, Sun J, Qi X, Sun J. Simultaneous modelling of car-following and lane-changing behaviours using deep learning. Transportation Research Part C: Emerging Technologies. 2019;104: 287-304. Available from: doi:10.1016/j.trc.2019.05.021 [Accessed 21 $1^{\text {th }}$ June 2020].

[70] Kita H. A merging-giveway interaction model of cars in a merging section: A game theoretic analysis. Transportation Research Part A: Policy and Practice. 1999;33(3-4): 305-312.

[71] Wang M, Hoogendoorn SP, Daamen W, van Arem B, Happee R. Game theoretic approach for predictive lane-changing and car-following control. Transportation Research Part C: Emerging Technologies. 2015;58(part A): 73-92. Available from: doi:10.1016/j. trc.2015.07.009 [Accessed 23 ${ }^{\text {th }}$ May 2020].

[72] Ali Y, Zheng Z, Haque M, Wang M. A game theory-based approach for modelling mandatory lane-changing behaviour in a connected environment. Transportation Research Part C: Emerging Technologies. 2019;106: 220-242. Available from: doi:10.1016/j.trc.2019.07.011 
[Accessed 26 ${ }^{\text {th }}$ April 2020].

[73] Ji A, Levinson D. A review of game theory models of lane changing. Transportmetrica A: Transport Science. 2020;16(3): 1628-1647. Available from: doi:10.1080/2 3249935.2020 .1770368 [Accessed 28 ${ }^{\text {th }}$ May 2020].

[74] Liu M, Shi J. A cellular automata traffic flow model combined with a BP neural network based microscopic lane changing decision model. Journal of Intelligent Transportation Systems. 2018;23(4): 309-318.

[75] Choi S, Yeo H. Framework for simulation-based lane change control for autonomous vehicles. 2017 IEEE Intelligent Vehicles Symposium (IV) 11-14 June 2017, Los Angeles, CA, USA.

[76] Cao P, Hu Y, Miwa T, Wakita Y, Morikawa T, Liu X. An optimal mandatory lane change decision model for autonomous vehicles in urban arterials. Journal of Intelligent Transportation Systems. 2017;21(4): 271-284. Available from: doi:10.1080/15472450.2017.1315805 [Accessed 22 $2^{\text {th }}$ May 2020].

[77] Rahman S, Abdel-Aty M, Lee J, Rahman H. Safety benefits of arterials' crash risk under connected and automated vehicles. Transportation Research Part C: Emerging Technologies. 2019;100: 354-371. Available from: doi:10.1016/j.trc.2019.01.029 [Accessed 11 ${ }^{\text {th }}$ April 2020].

[78] HuX, Sun J. Trajectory optimization of connected and autonomous vehicles at a multilane freeway merging area. Transportation Research Part C: Emerging Technologies. 2019;101: 111-125 Available from: doi:10.1016/ j.trc.2019.01.029 [Accessed 16 ${ }^{\text {th }}$ May 2020].

[79] Vechione M, Balal E, Long Cheu R. Comparisons of mandatory and discretionary lane changing behaviour on freeways. International Journal of Transportation Science and Technology. 2018;7(2): 124-136. Available from: doi:10.1016/j.ijtst.2018.02.002 [Accessed $17^{\text {th }}$ April 2020].

[80] Teknomo K. Microscopic Pedestrian Flow Characteristics: Development of an Image Processing Dana Collection and Simulation Model. PhD Thesis. Tohoku University; 2002.

[81] Blue V, Adler J. Emergent Fundamental Pedestrian Flows From Cellular Automata Microsimulation. Transportation Research Record. 1998;1644: 29-36. Available from: doi:10.3141/1644-04. [Accessed $6^{\text {th }}$ May 2019].

[82] Gipps P, Marksjö B. A micro-simulation model for pedestrian flows. Mathematics and Computers in Simulation. 1985;27: 95-105. Available from: doi:10.1016/03784754(85)90027-8. [Accessed $8^{\text {th }}$ April 2019].

[83] Xu W, Liu L, Zlatanova S, Pernard W, Xiong Q. A pedestrian tracking algorithm using grid-based indoor model. Automation in Construction. 2018;92: 173-187. Available from: doi:10.1016/j.autcon.2018.03.031 [Accessed $23^{\text {th }}$ April 2020].

[84] Okazaki S, Matsushita S. A Study of Simulation Model for Pedestrian Movement with Evacuation and Queuing. Proceedings of the International Conference on Engineering for Crowd Safety, 1993, London, England. p. 271-280.

[85] Helbing D, Molnar P. Social Force Model for pedestrian dynamics. Physical Review E. 1995;51: 4282-4286.

[86] Wang P. Understanding social-force model in psychological principles of collective behaviours. To be published in Physics and Society. [Preprint] 2016. Available from: https://arxiv.org/abs/1605.05146. [Accessed: $12^{\text {th }}$ April 2019].

[87] Antonini G, Bierlaire M, Weber M. Discrete choice models of pedestrian walking behaviour. Transportation Research Part B: Methodological. 2006;40(8): 667-687. Available from: doi:10.1016/j.trb.2005.09.006 [Accessed 20 ${ }^{\text {th }}$ April 2020].

[88] Lovas, GG. Modelling And Simulation Of Pedestrian Traffic Flow. Transportation Research Part B: Methodological. 1994;28(6): 429-443.

[89] Ossen S, Hoogendoorn SP. Heterogeneity in car-following behaviour: Theory and empirics. Transportation Research Part C: Emerging Technologies. 2011;19(2): 182-195.

[90] Sarvi M. Heavy commercial vehicles following behaviour and interactions with different vehicle classes. Journal of Advanced Transportation. 2013;47: 572580. Available from: doi:10.1002/atr.182 [Accessed $25^{\text {th }}$ April 2019].

[91] Aghabayk K, Sarvi M, Young W. Attribute selection for modelling driver's car-following behaviour in heterogeneous congested traffic conditions. Transportmetrica A: Transport Science. 2014;10(5): 457-468.

[92] Lu Z, Fu T, Fu L, Shiravi S, Jiang C. A video-based approach to calibrating car-following parameters in VISSIM for urban traffic. International Journal of Transportation Science and Technology. 2016:5(1): 1-9. Available from: doi:10.1016/j.ijtst.2016.06.001 [Accessed 16 ${ }^{\text {th }}$ April 2019].

[93] Brockfeld E, Kühne RD, Wagner P. Calibration and validation of microscopic traffic flow models. Transportation Research Record Journal of the Transportation Research Board. 2004;1876: 62-70.

[94] St-Aubin P, Saunier N, Miranda-Moreno L. Large-scale automated proactive road safety analysis using video data. Transportation Research Part C: Emerging Technologies. 2015;58: 363-379.

[95] Durrani U, Lee C. Calibration and Validation of Psychophysical Car-Following Model Using Driver's Action Points and Perception Thresholds. Journal of Transportation Engineering, Part A: Systems. 2019;145(9). Available from: doi:10.1061/JTEPBS.0000264 [Accessed 23 $3^{\text {th }}$ April 2020].

[96] Menneni S, Sun C, Vortisch P. Microsimulation Calibration Using Speed-Flow Relationship. Transportation Research Record: Journal of the Transportation Research Board. 2008;2088: 1-9. Available from: doi:10.3141/2088-01

[97] Sharma H, Swami B. MOE-analysis for oversaturated flow with interrupted facility and heterogeneous traffic for urban roads. International Journal of Transportation Science and Technology. 2012;1(3): 287-296.

[98] Ištoka Otković I, Tollazzi T, Šraml M. Calibration of microsimulation traffic model using neural network approach. Expert Systems with Applications. 2013;40: 5965-5974. Available from: doi:10.1016/ 
j.eswa.2013.05.003 [Accessed 20 $0^{\text {th }}$ April 2019].

[99] Hollander Y, Liu R. The principles of calibrating traffic microsimulation models. Transportation. 2008;35(3): 347-362. Available from: doi:10.1007/s11116-0079156-2 [Accessed 20 th December 2019].

[100] Feliciani C, Gorrini A, Crociani L, Vizzari G, Nishinari $\mathrm{K}$, Bandini S. Calibration and validation of a simulation model for predicting pedestrian fatalities at unsignalized crosswalks by means of statistical traffic data. Journal of Traffic and Transportation Engineering (English Edition). 2020;7(1): 1-18. Available from: doi:10.1016/j. jtte.2019.01.004 [Accessed 29 ${ }^{\text {th }}$ April 2020].

[101] United States Department of Transportation Federal Highway Administration. Surrogate Safety Assessment Model and Validation: Final Report. Available from: https:/www.fhwa.dot.gov/publications/research/safety/08051/index.cfm [Accessed $18^{\text {th }}$ May 2020]. 